\title{
BMJ Open Where to buy OTC medications? A cross- sectional survey investigating consumers' confidence in over-the-counter (OTC) skills and their attitudes towards the availability of OTC painkillers
}

\author{
A E M Brabers, ${ }^{1}$ L Van Dijk, ${ }^{1}$ M L Bouvy, ${ }^{2,3}$ J D De Jong ${ }^{1}$
}

To cite: Brabers AEM, Van Dijk L, Bouvy ML, et al. Where to buy OTC medications? A cross-sectional survey investigating consumers' confidence in over-the-counter (OTC) skills and their attitudes towards the availability of OTC painkillers. BMJ Open 2013;3:e003455. doi:10.1136/bmjopen-2013003455

- Prepublication history for this paper is available online. To view these files please visit the journal online (http://dx.doi.org/10.1136/ bmjopen-2013-003455).

Preliminary results of part of this manuscript were presented at the 4th European Public Health Conference: 'Public Health and WelfareWelfare Development and Public Health' from 9 to 12 November 2011, Copenhagen. An abstract is available in the Eur J Public Health, 21 (2011) Suppl 1, p.129.

Received 21 June 2013 Revised 29 August 2013 Accepted 30 August 2013

For numbered affiliations see end of article.

Correspondence to A E M Brabers; a.brabers@nivel.nl

\section{ABSTRACT}

Objective: To examine consumers' confidence in their own, and also in other people's, over-the-counter (OTC) skills and to describe their attitude towards the availability of OTC painkillers. Moreover we examined the association between confidence in OTC skills and attitudes.

Design: Cross-sectional survey. Mixed methods (postal and electronic) self-administered questionnaire.

Participants: Members of the Dutch Health Care Consumer Panel.

Main outcome measures: Consumers' confidence in their own, and in other people's, OTC skills was examined. Confidence was measured by three questions regarding obtaining information on, choosing and using OTC medication. Consumers' attitudes towards availability were assessed using six safety profiles, by asking which channel consumers prefer for each profile.

Results: The response rate was $68 \%(n=972)$. Consumers feel confident about their own OTC skills (mean 3.74; 95\% Cl 3.69 to 3.79, on a 5-point Likert scale), but have less confidence in OTC skills of others (mean 2.92; 95\% Cl 2.88 to 2.96). Consumers are conservative in their attitudes towards the availability of OTC painkillers. Most consumers prefer painkillers to be available exclusively in pharmacies $(41-71 \%$ per profile indicated pharmacy only). Moreover, there is an association between confidence in OTC skills and attitudes ( $p=0.005 ; \beta=-0.114)$. Consumers who are more confident about their own OTC skills prefer OTC painkillers to be more generally available.

Conclusions: Consumers feel confident about their own OTC skills. However, they would prefer painkillers with safety profiles resembling those currently available OTC, to be available as OTC in pharmacies exclusively. Consumers' confidence in the OTC skills of others is more consistent with their attitudes towards availability of OTC painkillers. Until consumers themselves realise that they are also one of the others, they may overestimate their own OTC skills, which may entail health risks.

\section{BACKGROUND}

The need to save on healthcare spending and the trend to enhance self-care have led to more emphasis on patients taking their

\section{ARTICLE SUMMARY}

Strengths and limitations of this study

- The large sample size and the response rate of almost $70 \%$ participants and the inclusion of an indirect measurement of the concept 'attitudes towards availability' in our questionnaire instead of asking directly where certain specific over-the-counter (OTC) painkillers should be available. Another strength is that this study addresses a relatively unexplored area.

- Unable to make a comparison between a direct as well as indirect measurements and unable to link our results to the actual self-medication behaviour of the respondents. In addition, the study only relates to painkillers, the most used OTCs in The Netherlands.

own responsibility for the management of minor ailments, including the use of medication that is available without a prescription. ${ }^{12}$ Today, a wide range of conditions can be treated using medications that are available over-the-counter (OTC). Some examples of categories of medicines that have been reclassified to non-prescription medication in many countries are non-steroidal antiinflammatory drugs (NSAIDs), antifungal creams and laxatives. However, inappropriate use of OTC medications entails considerable health risks. Several studies demonstrated that inappropriate use results in drug intoxication, drug interactions, side effects and increased healthcare costs as a consequence of extra visits to a doctor and hospitalisation. $^{3-7}$ Nevertheless, in many countries, increasingly more drugs that were previously only available on prescription are being switched to OTC status. ${ }^{2} 89$ The United States Government Accountability Office studied five countries (the UK, the USA, The Netherlands, Italy and Australia) and determined how medicines were classified in 
each. They found that since 1995 all these countries have increased OTC availability. This is due either to changes in the classification of non-prescription drugs or to the reclassification of medications into less restrictive classes. ${ }^{10}$

In the Netherlands, the availability of OTC drugs increased when the Dutch government changed the system for OTC medications. The Dutch healthcare policy is based on ideas that independent and critical consumers require an increased availability of OTC medication in order to select a particular drug themselves. Since the introduction of the Medicines Act on 1 July 2007, three categories of non-prescription drugs have been specified: (1) pharmacy only; (2) pharmacy or chemist only and (3) general sales. ${ }^{11}$ Before July 2007, the third category did not exist. In the Netherlands, there is a distinction between pharmacies and chemists. Pharmacies are run by a pharmacist and are able to sell all prescription (when a prescription is given) and non-prescription drugs, while chemists are run by a druggist, who requires less training than a pharmacist and is able to sell many but not all nonprescription drugs. ${ }^{10}$ When introducing the new legislation, the Dutch government argued that consumers are well informed and know how to use OTC drugs appropriately. ${ }^{11}{ }^{12}$ This assumption was not supported by international literature. Earlier research, mainly focused on analgesics, observed that consumers appear to be unaware of how to use OTC medications appropriately. ${ }^{4-6}{ }^{13-16}$

There has been little research conducted into how consumers themselves perceive their skills in using OTC medications appropriately. It is important to gain some insight into areas such as overestimating OTC skills as this may result in risks to health. The purpose of the present study was to examine consumers' confidence in OTC skills. We examined consumers' confidence, both in their own OTC skills, and in those of others. This is because previous research has shown that 'people tend to think positively of themselves, often to unrealistic degrees'. ${ }^{17}$ Moreover, the literature demonstrated that consumers' estimates of their peers' attitudes and behaviours tend to be roughly accurate. ${ }^{17}$ Furthermore, we examined which channel consumers prefer with regard to the availability of OTC painkillers. Finally, we examined the association between consumers' confidence in OTC skills and their attitudes towards the availability of OTC painkillers, as we expected that confident consumers prefer them to be more generally available.

\section{METHODS}

\section{Setting}

Data were collected in the Dutch Health Care Consumer Panel. ${ }^{18-20}$ This panel aims to measure opinions on and knowledge of healthcare as well as expectations and experiences with healthcare at a national level. At the time of the study (June 2010), the Consumer Panel consisted of approximately 3000 people aged 18 years and older. Each individual member of the panel receives a questionnaire approximately three times a year and can quit the panel at any time. There is no possibility for consumers to sign up for the panel with their own initiative. The panel is renewed on a regular basis. Renewal is necessary to make sure that members do not develop specific knowledge of, and attention for, healthcare issues, and that no questionnaire-fatigue occurs. Moreover, renewal compensates for panel members who, for example, have died or moved without providing information about the new address. To recruit new panel members an address file is bought from an address supplier. As a result, possible new members are sampled at random from the general population in the Netherlands. Sampled people receive an information letter about the panel and are called within a week after receiving that letter. If they are interested, they receive a questionnaire on their demographic characteristics. When that questionnaire is returned, they are considered members of the panel. Data are anonymously processed, and the protection of the data collected is registered with the Dutch Data Protection Authority (nr. 1262949).

\section{Questionnaire}

The questionnaire was developed based on the wider literature and experiences of the research team. In total, the questionnaire included 36 questions (with largely predefined answer categories of responses) focusing on different aspects of OTC medications. While a pilot study was not conducted due to time constraints, face and content validity of the questionnaire were assessed by two senior researchers (LVD and MB). In June 2010, the self-administered questionnaire was sent to 1422 panel members. According to their previously stated preference, 671 members received a questionnaire by post and 751 through the internet. Using a mixed methods approach helped to ensure that certain groups were not excluded from the study and may also have an increased response rate. Other methods used to increase the response rate included sending two electronic reminders and one postal reminder to panel members who had not responded yet. The closing date of the questionnaire was late July 2010.

\section{Demographic characteristics}

The demographic characteristics of the panel members including their age, gender, level of education, selfreported general health and whether they work(ed) or never worked in healthcare are documented at the start of the panel membership and are updated annually. Level of education reflected the highest level of education completed and was classified as low; middle and high (see also table 1). To measure self-reported general health one question from the SF-36 was used. In the SF-36 the answer categories (bad; fair; good; very good; excellent) are not defined, therefore we did not provide any explanation of these terms either. 


\section{Use of OTC drugs}

The respondents were asked how long it had been since they had used OTC medications. We defined OTC medications in the questionnaire as follows: 'OTC medications are medicines that you can buy at pharmacies and chemists without a doctors' prescription. In addition, you can buy some of these medicines at supermarkets and petrol stations. Examples of OTC medications are painkillers, such as paracetamol or ibuprofen. Homeopathic medicines, nutritional supplements and contraceptives are not considered to be OTC medications'. Based on their answers, we generated a dichotomous variable for the use of OTC drugs in the year prior to the questionnaire $(1=y e s ; 0=$ no). In addition, the respondents who had used OTC drugs in the year prior to the questionnaire were asked what kind of categories (predefined) of OTC drugs they had used in that year. All questions had predefined categories of answers.

\section{Confidence}

Confidence was measured using three questions with regard to obtaining information on, choosing and using OTC medications. These were: (1) 'I am able to make an appropriate choice between different types and brands of OTC drugs'; (2) 'I know exactly how to use OTC drugs in a safe way' and (3) 'When I try to get advice on OTC drugs, I can easily get the right information'. We used the same three items to examine consumers' confidence in the OTC skills of others, for example, asking if: 'Others are able to make an appropriate choice between different types and brands of OTC drugs'. All items had a five-point Likert scale ranging from strongly disagree to strongly agree. We evaluated for both scales whether the three items measured a single concept by calculating the internal consistency given by Cronbach's $\alpha$. Only the respondents who filled out all three items were included (own: $\mathrm{n}=951$; others: $\mathrm{n}=949$ ). The internal consistency was good (for both scales Cronbach's $\alpha 0.81$ ). Subsequently, a mean score was calculated for the respondents who filled out all three items ranging from 1 to 5 , in which higher scores indicated greater confidence.

\section{Attitudes towards availability}

We presented six safety profiles of painkillers in order to assess consumers' attitudes towards availability. Each profile described a painkiller having properties that resemble current available painkillers in the Netherlands (eg, paracetamol and ibuprofen). In the Netherlands, paracetamol $500 \mathrm{mg}$; several combinations of paracetamol $500 \mathrm{mg}$ with caffeine and/or vitamin C; several combinations of paracetamol $250 \mathrm{mg}$ with propyhenazon $250 \mathrm{mg}$ or acetylsalicylic acid $250 \mathrm{mg}$; ibuprofen 200 and $400 \mathrm{mg}$; naproxen 220 and $275 \mathrm{mg}$; diclofenac $12.5 \mathrm{mg}$; ketoprofen $25 \mathrm{mg}$; acetylsalicylic acid $500 \mathrm{mg}$ and carbasalate calcium $600 \mathrm{mg}$ are all available OTC in oral formulations. In addition,

Table 1 Demographic characteristics of the respondents and the Dutch population aged 18 years and older

\begin{tabular}{|c|c|c|c|c|}
\hline & \multicolumn{2}{|c|}{ Respondents } & \multicolumn{2}{|c|}{$\begin{array}{l}\text { Dutch population aged } \\
18 \text { years and older* }\end{array}$} \\
\hline & $\overline{\mathbf{N}}$ & Per cent & \multicolumn{2}{|l|}{ Per cent } \\
\hline Gender & 972 & & & \\
\hline Male & 424 & 43.6 & 49.0 & \\
\hline Female & 548 & 56.4 & 51.0 & \\
\hline Age (years) & 972 & & & \\
\hline 18-39 & 88 & 9.1 & 35.3 & \\
\hline $40-64$ & 527 & 54.2 & 45.3 & \\
\hline 65 and older & 357 & 36.7 & 19.5 & \\
\hline Education & 948 & & & \\
\hline Low (none, primary school or prevocational education) & 184 & 19.4 & 33.8 & \\
\hline Middle (secondary or vocational education) & 448 & 47.3 & 40.5 & \\
\hline High (professional higher education or university) & 316 & 33.3 & 25.7 & \\
\hline Self-reported general health & 965 & & & \\
\hline Poor/fair & 175 & 18.1 & Less than good $\dagger$ & 18.6 \\
\hline Good & 487 & 50.5 & Good & 52.7 \\
\hline Excellent/very good & 303 & 31.4 & Very good & 28.8 \\
\hline Working in healthcare & 919 & & & \\
\hline No, never worked in healthcare & 663 & 72.1 & Not available & \\
\hline Yes, I am currently working in healthcare & 119 & 13.0 & Not available & \\
\hline Yes, I have worked in healthcare in the past & 137 & 14.9 & Not available & \\
\hline Use of OTC drugs in the year prior to the questionnaire & 960 & & & \\
\hline No & 160 & 16.7 & Not available & \\
\hline Yes & 800 & 83.3 & Not available & \\
\hline
\end{tabular}


diclofenac gel is a registered OTC as topical preparation, however, only for pain due to arthrosis of finger and knees. The profiles were descriptions of possible adverse effects of their use, inappropriately or not, and were based on information reflected in patient information leaflets and summaries of product characteristics. They were constructed by one of the research members (MB), who is a pharmacist with special interest in OTC medication and author of a standard Dutch handbook of self-medication. We focused on OTC painkillers because painkillers are among the most commonly used medications ${ }^{141621}$ and their inappropriate use can cause serious side

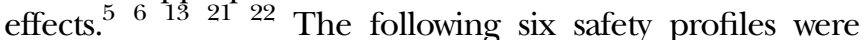
included: (1) 'No side effects when used as directed, but taking too many tablets can cause serious damage'; (2) 'Mild side effects, such as stomach and intestinal problems, but never serious side effects'; (3) 'In rare cases (less than 1/1000) people suffer serious side effects, like gastrointestinal bleeding'; (4) 'Safe when used normally, but potentially serious side effects when used in combination with certain prescription drugs'; (5) 'Can be used safely by most people, but potentially serious side effects when used by elderly people and those with severe concomitant diseases' and (6) 'Can be used safely by most people, but potentially serious side effects when used by children'. We asked respondents to indicate their preferences for the availability of painkillers with the above described profiles, with the following options: general sales (defined in the questionnaire as supermarket/petrol station), chemist, pharmacy only and prescription only. It should be noted that in the questionnaire the options were used in a different order, namely: pharmacy only, chemist, general sales and prescription only. The answer options were based on the Dutch Medicines Act. The options were scored as 1 general sales; 2 chemist; 3 pharmacy only and 4 prescription only. In addition, items scored as, 'I don't know', were recorded as missing (in total 115 times, 16-25/profile). To evaluate whether the six items measured a single concept, we calculated the internal consistency given by Cronbach's $\alpha$. Respondents who did not fill out all profiles were excluded from the analyses (excluded $n=228$, included $n=744$ ). The excluded respondents did not differ significantly from the respondents included with regard to their demographics. However, they were significantly more restrictive in their preferences for the safety profiles for which they did provide an answer. Factor analysis of the data identified one factor and the internal consistency was good (Cronbach's $\alpha$ 0.77). Subsequently, a mean score was calculated for the items for the respondents who filled out all six profiles ranging from 1 to 4 , whereby higher scores indicated a greater preference for restricting availability.

\section{Statistical analyses}

First, we performed descriptive statistics. Then, by means of $\mathrm{t}$ tests and one-way analyses of variance (ANOVA; $\mathrm{p}<0.01$ ), we tested the association between the outcomes (consumers' confidence in their own OTC skills and consumers' attitudes) and demographic characteristics (gender, age in three categories, level of education, selfreported general health and whether they work(ed) or never worked in healthcare) and the use of OTC medications. Finally, we conducted a regression analysis to investigate the association between the dependent variable, consumers' attitudes, and the independent variables, consumers' confidence in their own OTC skills, demographic characteristics and use of OTC medications $(\mathrm{p}<0.05)$. We repeated this association using the total number of times respondents scored the options 'pharmacy only' and 'prescription only' (ranging from 0 to 6), instead of their mean scores, as a dependent variable. In the regression analyses, categorical variables were recoded into dummy variables. All statistical analyses were carried out using STATA, V.12.1.

\section{RESULTS}

In total, 972 panel members returned the questionnaire (response rate $68 \%$ ). The response to the online questionnaire was lower than the written questionnaire $(62 \%$ and $76 \%$, respectively). More than half $(56 \%)$ of the respondents were women (table 1 ). The age category 40-64 years included 54\% of the respondents. Almost half $(47 \%)$ had a middle level of education. General health was self-reported as excellent/very good in $31 \%$ of the cases. Of the respondents $72 \%$ had never worked in healthcare. Compared with the Dutch population aged 18 years and older ${ }^{18}$ it was mainly young people (18-39 years) who were under-represented in the group of respondents (see table 1 ).

\section{Use of OTC drugs}

Among the respondents, $83 \%$ used OTC medications in the year prior to the questionnaire (see table 1). Almost all respondents who had used OTC drugs in the year prior to the questionnaire indicated that they had used pain and antipyretic medicines (97\%). Furthermore, $76 \%$ of the respondents who had used OTC drugs in the year prior to the questionnaire indicated that they had used medicines for coughs, colds, flu and a sore throat.

\section{Confidence}

The mean score for consumers' confidence in their own OTC skills was 3.74 (95\% CI 3.69 to 3.79, on a 5-point Likert scale), indicating that respondents felt quite confident about their own OTC skills. Clearly, the respondents felt less confident about the OTC skills of others (mean score 2.92 and $95 \%$ CI 2.88 to 2.96 ).

As reflected in figure 1,7 of the 10 respondents agreed, or strongly agreed, that they are able to make an appropriate choice between different types and brands of OTC drugs. Only $16 \%$ of them thought that others are able to make an appropriate choice. Furthermore, $65 \%$ of the respondents agreed, or strongly agreed, that they know exactly how to use OTC drugs in a safe way, while only $11 \%$ of them thought that others know how 
to use OTC drugs safely. Lastly, $76 \%$ of the respondents agreed, or strongly agreed, that they can easily get the right information when trying to get advice on OTC drugs, compared with $30 \%$ of them who believed that others are able to get the right information.

ANOVAs and t tests showed significant but modest differences between consumers' confidence in their own OTC skills and gender, age, level of education and whether they work(ed) or never worked in healthcare. Women felt slightly more confident about their own OTC skills than men. Furthermore, the elderly ( $\geq 65$ years) and people with a low level of education had slightly less confidence than younger people and people with a middle and high level of education. People who currently work in healthcare or have worked in healthcare in the past felt slightly more confident about their own OTC skills than people who have never worked in healthcare. In addition, ANOVA showed that people who had used OTC medications in the year prior to the questionnaire were more confident about their own OTC skills than those who had not used OTC medications in the year prior to the questionnaire (mean 3.84 respectively $3.24, \mathrm{p}<0.001$ ).

\section{Attitudes towards availability}

Table 2 shows that the pharmacy is often mentioned as preferred channel where painkillers with the described profiles should be available (range $41-71 \%$ ). For five of the six profiles most respondents preferred that painkillers with such a profile should be available exclusively in pharmacies. Only 1-8\% chose supermarkets or petrol stations as their preferred option. ANOVAs and t tests showed significant but modest differences between consumers' attitudes and age and level of education. The elderly ( $\geq 65$ years) were more restrictive in their preferences for availability than younger people. Moreover, people with a low level of education were more restrictive in their preferences than people with a middle and high level of education.

The last research question focused on the association between consumers' confidence in their own OTC skills and their attitudes towards availability (see table 3 ). The regression analysis showed that respondents who were more confident about their own OTC skills preferred OTC painkillers to be more generally available. This association was observed in addition to the effects of age and the level of education already mentioned. The association between own OTC skills and attitudes towards availability was also found when we performed an additional regression analysis, in which we used the total number of times respondents scored the options 'pharmacy only' and 'prescription only' as a dependent variable.

\section{DISCUSSION}

\section{Principal findings}

Consumers feel confident about their own OTC skills, but they have less confidence in the OTC skills of others. In other words, consumers presume that, compared to themselves, other people are less able to use self-medication appropriately. Although consumers are confident, they are conservative in their attitudes towards the general availability of OTC painkillers. Most consumers prefer that painkillers with the described profiles (eg, paracetamol and ibuprofen) should be available in pharmacies exclusively. Currently, painkillers with profiles similar to those described are available for general sale in most European countries, including the Netherlands. Finally, we observed that more confident consumers preferred OTC painkillers to be more generally available.

\section{Comparisons with other studies}

There appears to be a discrepancy between our findings on the public perception about their own OTC skills and earlier research on the public awareness, perception and knowledge of OTC medication. While our study showed that consumers have high confidence in their own skills, previous studies found that consumers are unaware of the fact that OTC medications can cause adverse events when used with other medications ${ }^{5} 23$ and also of the toxicities of OTC medications. ${ }^{4} 14$ Neither do they know, nor are concerned, about the potential side effects of OTC analgesics. ${ }^{13}{ }^{14}$ They perceive OTC drugs as safe ${ }^{1415}$ and 'too weak to cause any
Figure 1 Consumers' confidence in their own over-the-counter (ОTC) skills and in the OTC skills of others, Choosing: I am/others are able to make an appropriate choice between different types and brands of OTC drugs, Using: l/others know exactly how to use OTC drugs in a safe way, Obtaining information on: When l/others try to get advice on OTC drugs, l/others can easily get the right information.

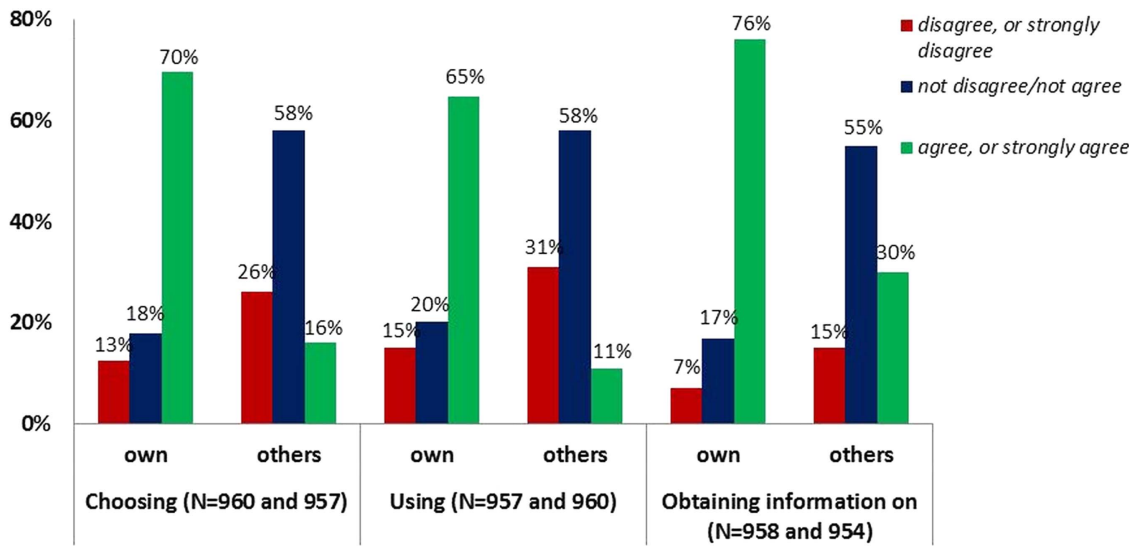




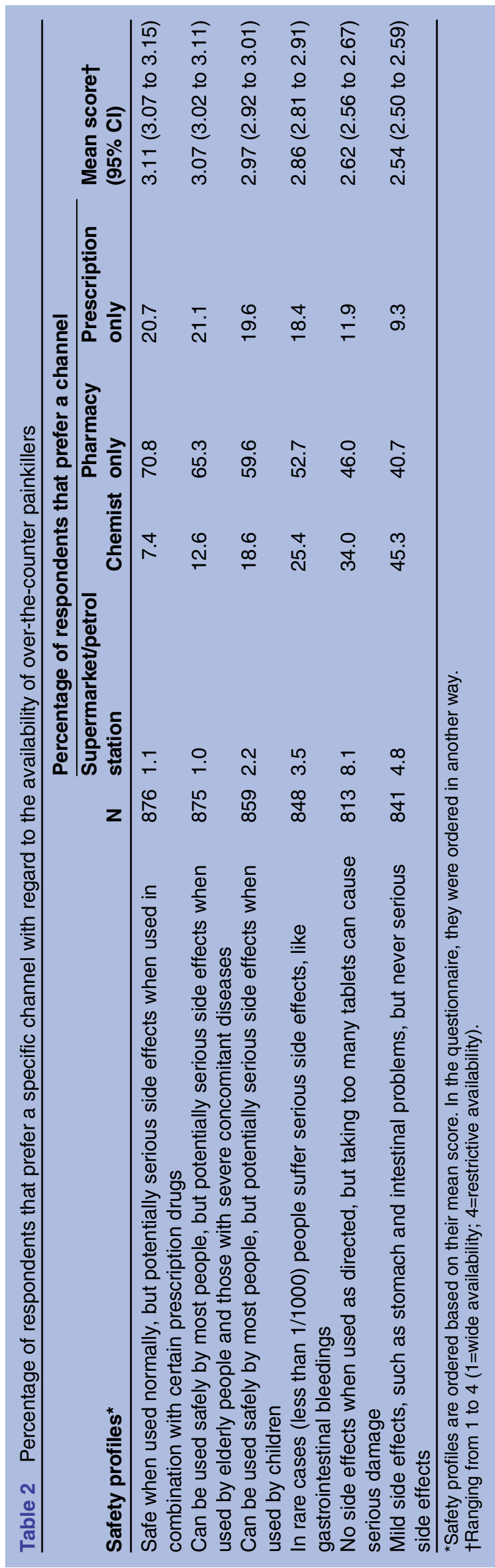

real harm'. ${ }^{6}$ In addition, a recent study in Australia observed that fewer people are using NSAIDs appropriately according to the label, since ibuprofen has become available outside the pharmacy. ${ }^{16}$ Summarised, while previous studies show that consumers seem to be unaware of how to use OTC medications appropriately our study shows that consumers are convinced they know how to use OTC medications appropriately. Yet, the confidence consumers have in the skills of others seems more consistent with the literature. It also probably better connects to reality, since, in general, the estimates of consumers regarding their peers' attitudes and behaviours tend to be roughly accurate. ${ }^{17}$ Moreover, the confidence consumers have in the skills of others is in line with their attitudes towards availability of OTC painkillers. It appears that consumers have taken into account in their attitudes the confidence, or lack of it, that they have in the OTC skills of others. The assumption of the Dutch government that consumers prefer a less restrictive availability is not supported by our findings when consumers are confronted with safety information on medication. Nevertheless, in many countries an increasing number of drugs that were previously only available on prescription have been switched to OTC status. ${ }^{2} 89$

\section{Implications}

Confidence in self-medication does not imply that the use of OTC medications is always optimal or appropriate. ${ }^{24}$ The difference between consumers' confidence in their own skills compared with those of others indicate that some OTC users may be overconfident of their own OTC skills. This view is supported by the fact that consumers would like to limit the availability of OTC drugs with profiles that match currently widely available OTC drugs. This suggests that not all consumers are able to comprehend the proper use of OTC drugs which may entail health risks. For example, Leendertse et $a \ell^{25}$ observed that NSAIDs (among which also OTC drugs) are one of the medicines associated most often with potentially preventable medication-related hospital admissions. Moreover, Pirmohamed ${ }^{26}$ observed that, among others, NSAIDs were most commonly implicated in admissions related to adverse drug reactions. Furthermore, a Dutch study showed that during the last decade there had been an increase in requests on paracetamol poisoning to the National Poisons Information Center. ${ }^{27}$ There also have been some concerns regarding switching the status of prescription drugs to OTC availability. Examples of such concerns are an inaccurate diagnosis by patients and delay in obtaining medical assistance. ${ }^{28}$ We were unable to link our results to the actual self-medication behaviour of the respondents. Therefore, further research is recommended to examine this.

The fact that inappropriate use of medication entails health risks led to recommendations to increase the risk awareness and knowledge among the public, and to educate them about OTC medication and its potential risks. ${ }^{6} 13141629$ The question is whether people are either 
Table 3 Regression model for attitudes towards availability $(n=672)$

\begin{tabular}{|c|c|c|}
\hline & $\beta^{*}$ & p Value \\
\hline \multicolumn{3}{|l|}{ Availability (1=wide; 4=restrictive) } \\
\hline Confidence (1=low; 5=high) & -0.114 & 0.005 \\
\hline Gender ( $0=$ man; $1=$ woman $)$ & 0.010 & 0.807 \\
\hline Age & 0.102 & 0.012 \\
\hline \multicolumn{3}{|l|}{ Level of education } \\
\hline Low & \multicolumn{2}{|c|}{ Reference level } \\
\hline Middle & -0.118 & 0.024 \\
\hline High & -0.242 & 0.000 \\
\hline \multicolumn{3}{|l|}{ Self-reported general health } \\
\hline Poor/fair & \multicolumn{2}{|c|}{ Reference level } \\
\hline Good & 0.028 & 0.599 \\
\hline Excellent/very good & -0.011 & 0.838 \\
\hline $\begin{array}{l}\text { Work in healthcare }(0=\text { never worked in healthcare; } 1=\text { currently working } \\
\text { in healthcare/worked in healthcare in past) }\end{array}$ & -0.038 & 0.358 \\
\hline Use of OTC drugs in year prior to questionnaire $(0=$ no; $1=y e s)$ & -0.010 & 0.813 \\
\hline Constant & & 0.000 \\
\hline $\begin{array}{l}\text { Bold type indicates } p<0.05 \text {. } \\
\text { Adjusted } R^{2} 0.07 \text {. } \\
{ }^{*} \text { Standardised coefficients. } \\
\text { OTC, over-the-counter. }\end{array}$ & & \\
\hline
\end{tabular}

unable to understand and find the correct information, or whether they do not want, read, search or ask for this information. Therefore, it is not clear yet, how to increase public awareness. What seems clear is that consumers consider pharmacies as a safe environment, since most of them prefer the painkillers described to be available in pharmacies exclusively. This is similar to findings of an earlier study where it was found that Dutch consumers consider pharmacists as the most reliable source of information regarding OTC medication. ${ }^{30}$ Although Dutch consumers expect to be provided with reliable information from pharmacies, it is possible that there are differences between pharmacies with regard to the quality of their advice. Furthermore, in 2010, $88 \%$ of the Dutch adult population put much trust in pharmacists. ${ }^{31}$ As a result, pharmacists can have an important role in questioning and informing patients about OTC medications.

\section{Strengths and limitations of the study}

This study addresses a relatively unexplored area. An important strength of our study is the large sample size and the response rate of almost $70 \%$ participants. However, the respondents in our study are not fully representative of the adult Dutch population aged 18 plus. Therefore, we performed analyses to see whether there are differences between groups of consumers. We observed some small but significant differences. However, they do not appear to affect our conclusions. We included an indirect measurement of the concept 'attitudes towards availability' in our questionnaire instead of asking directly where certain specific OTC painkillers should be available. Earlier research in The Netherlands demonstrated that when trade names of painkillers are presented to consumers, they judge them as safe. More than $95 \%$, respectively $70 \%$, of the consumers considered paracetamol and ibuprofen as safe, or very safe. ${ }^{32}$ Unfortunately, we did not include direct as well as indirect measurements in our questionnaire, as we are now not able to make a comparison between both measurements. We also did not provide information on the pack sizes/quantity in the questionnaire. Providing such information might influence the attitude towards availability of the respondents. It could, for example, be assumed that consumers prefer a more restrictive availability for larger pack sizes of OTC medicines. Another possible limitation might be that the study only relates to painkillers, albeit those are the most used OTCs in the Netherlands. Furthermore, we did not include internet as a channel in our questionnaire, because this study was part of a policy evaluation in which only the official Dutch sales channels were evaluated. With the increasing growth of internet pharmacy, it would be interesting to include this channel in further research. Another possible limitation is that we excluded quite a considerable number of respondents $(\mathrm{N}=228)$, because they did not fill out all six safety profiles. The excluded respondents were more restrictive in their preferences, possibly implying a slight underestimation of the observed effects in our analyses. Finally, a possible limitation is that we were not able to conduct a pilot study due to time constraints. By performing a pilot study some issues could have been identified and addressed from the onset to improve the questionnaire.

\section{CONCLUSIONS}

This study aimed to examine consumers' confidence in OTC skills and their attitudes towards the availability of OTC painkillers. The Dutch government assumed that consumers are well informed, know how to use OTC medications appropriately, and prefer a wider availability. It could be questioned whether these assumptions are 
true. Consumers feel confident about their own OTC skills; however, they would prefer painkillers with safety profiles resembling currently available OTC painkillers, to be available as OTC in pharmacies exclusively. Furthermore, the confidence consumers have in the OTC skills of others seems more consistent with their attitude towards availability. Until consumers themselves realise they are also one of the others, they may overestimate their OTC skills, which may entail health risks.

\section{Author affiliations}

${ }^{1}$ NIVEL, Netherlands Institute for Health Services Research, Utrecht, The Netherlands

${ }^{2}$ Division Pharmacoepidemiology and Clinical Pharmacology, Utrecht Institute for Pharmaceutical Sciences (UIPS), Utrecht, The Netherlands

${ }^{3}$ SIR Institute for Pharmacy Practice and Policy, Leiden, The Netherlands

Acknowledgements The authors would like to thank the panel members of the Dutch Health Care Consumer Panel who participated in this study.

Contributors The study was devised and designed by LVD and MLB. JDDJ was responsible for the data collection in the Dutch Health Care Consumer Panel. AEMB performed the statistical analyses and drafted the manuscript. All other authors critically revised it and authors gave their final approval for the manuscript version to be published. All authors are responsible for the overall content as guarantors.

Funding Data collection of this study was funded by the Dutch Ministry of Health, Welfare and Sport (grant number: 2986633). The funder had no role in the design, execution and writing of the study.

Competing interests The authors received support for the data collection from the Dutch Ministry of Health, Welfare and Sport for the work submitted. AEMB and JDDJ declared that there was no financial relationship with any organisations that might have an interest in the submitted work in the previous 3 years. LVD received unrestricted grants from Bristol-Myers Squibb and Astra Zeneca for studies not related to this study in 2011 and 2012. MLB performed occasional consultancy work for both organisations of pharmacists, druggists and government. And all authors declared that there were no other relationships or activities that could appear to have influenced the submitted work

Ethics approval According to the Dutch law, no ethical approval was needed. The protection of the collected data is registered with the Dutch Data Protection Authority (nr. 1262949).

Provenance and peer review Not commissioned; externally peer reviewed.

Data sharing statement Data are available on request and subject to approval by the programme committee of the Dutch Health Care Consumer Panel. The questionnaire (in Dutch) is available on request from the authors.

Open Access This is an Open Access article distributed in accordance with the Creative Commons Attribution Non Commercial (CC BY-NC 3.0) license, which permits others to distribute, remix, adapt, build upon this work noncommercially, and license their derivative works on different terms, provided the original work is properly cited and the use is non-commercial. See: http:// creativecommons.org/licenses/by-nc/3.0/

\section{REFERENCES}

1. Barber N. Drugs: from prescription only to pharmacy only. BMJ 1993;307:640.

2. Blenkinsopp A, Bradley C. Over the counter drugs: patients, society, and the increase in self medication. BMJ 1996;312:629-32.

3. Schoenemann JH, Muller-Oerlinghausen B, Munter $\mathrm{KH}$, et al. Adverse drug reactions (ADR) causing hospital admissions. Pharmacoepidemiol Drug Saf 1998;7(Suppl 1):S1-3.

4. Huott MA, Storrow AB. A survey of adolescents' knowledge regarding toxicity of over-the-counter medications. Acad Emerg Med 1997;4:214-18.
5. Fendrick AM, Pan DE, Johnson GE. OTC analgesics and drug interactions: clinical implications. Osteopath Med Prim Care 2008;2:2.

6. Roumie CL, Griffin MR. Over-the-counter analgesics in older adults: a call for improved labelling and consumer education. Drugs Aging 2004;21:485-98.

7. Sheen CL, et al. Paracetamol toxicity: epidemiology, prevention and costs to the health-care system. QJM 2002;95:609-19.

8. Hanna LA, Hughes CM. Public's views on making decisions about over-the-counter medication and their attitudes towards evidence of effectiveness: a cross-sectional questionnaire study. Patient Educ Couns 2011;83:345-51.

9. Francis SA, Barnett N, Denham M. Switching of prescription drugs to over-the-counter status. Drugs Aging 2005;22:361-70.

10. US Government Accountability Office. Nonprescription drugs: considerations regarding a behind-the-counter drug class. Washington: GAO, 2009.

11. Van Dijk L, Van der Maat M, Salimans R, et al. Evaluatie van de indeling van zelfzorggeneesmiddelen en de rol van drogist en apotheek bij de verstrekking. Utrecht: NIVEL, 2010.

12. Van Dijk L, Vervloet M, Plas M, et al. Negatieve effecten van normaal en verkeerd gebruik van geneesmiddelen. Een literatuurstudie. Utrecht: NIVEL, 2005

13. Cham E, Hall L, Ernst AA, et al. Awareness and use of over-the-counter pain medications: a survey of emergency department patients. South Med J 2002;95:529-35

14. Wilcox CM, Cryer B, Triadafilopoulos G. Patterns of use and public perception of over-the-counter pain relievers: focus on nonsteroidal antiinflammatory drugs. J Rheumatol 2005;32:2218-24.

15. Clark D, Layton D, Shakir SAW. Monitoring the safety of over the counter drugs. We need a better way than spontaneous reports. BMJ 2001;323:706-7.

16. Stosic R, Dunagan $\mathrm{F}$, Palmer $\mathrm{H}$, et al. Responsible self-medication: perceived risks and benefits of over-the-counter analgesic use. Int $J$ Pharm Pract 2011;19:236-45.

17. Balcetis E, Dunning D. Considering the situation: why people are better social psychologists than self-psychologists. Self Identity 2011;12:1-15.

18. Brabers AEM, Reitsma-Van Rooijen M, De Jong JD. Consumentenpanel Gezondheidszorg. Basisrapport met informatie over het panel (2012). Utrecht: NIVEL, 2012.

19. Reitsma-van Rooijen M, De Jong JD, Rijken M. Regulated competition in health care: switching and barriers to switching in the Dutch health insurance system. BMC Health Serv Res 2011;11:95.

20. De Jong JD, van den Brink-Muinen A, Groenewegen PP. The Dutch health insurance reform: switching between insurers, a comparison between the general population and the chronically ill and disabled. BMC Health Serv Res 2008;8:58.

21. Singh G. Gastrointestinal complications of prescription and over-the-counter nonsteroidal anti-inflammatory drugs. Am J Ther 2000;7:115-21.

22. Butt JH, Barthel JS, Moore RA. Clinical spectrum of the upper gastrointestinal effects of nonsteroidal anti-inflammatory drugs. Am J Med 1988;84:5-14.

23. Indermitte J, Reber D, Beutler M, et al. Prevalence and patient awareness of selected potential drug interactions with self-medication. J Clin Pharm Ther 2007;32:149-59.

24. Hughes CM, McElnay JC, Fleming GF. Benefits and risks of self medication. Drug Saf 2001;24:1027-37.

25. Leendertse AJ. Frequency of and risk factors for preventable medication-related hospital admissions in the Netherlands. Arch Intern Med 2008;168:1890-6.

26. Pirmohamed M. Adverse drug reactions as cause of admission to hospital: prospective analysis of 18820 patients. BMJ 2004;329:15-19.

27. Van Dijk L, Van der Maat M, Bouvy M. Zelfzorggeneesmiddelen: actieve voorlichting over zelfzorg nodig. Aantal paracetamolvergiftigingen gestegen. Pharmaceutisch Weekblad 2010;146:18-20.

28. Wood AJJ, Brass EP. Changing the status of drugs from prescription to over-the-counter availability. N Engl J Med 2001;345:810-16.

29. Calamusa A, Di Marzio A, Cristofani R, et al. Factors that influence Italian consumers' understanding of over-the-counter medicines and risk perception. Patient Educ Couns 2012;87:395-401.

30. Brinkman ACA, Vervloet M, Van Dijk L, et al. Evaluatie reclamebesluit geneesmiddelen. Hague: ZonMw, 2008.

31. Brabers AEM, Reitsma-van Rooijen M, De Jong JD. Barometer Vertrouwen in de gezondheidszorg. Utrecht: NIVEL, 2013:8-14. http://www.nivel.nl/consumentenpanel-gezondheidszorg. Ref Type: Online Source.

32. TNS/Nipo. Advisering bij zelfzorgeneesmiddelen in drogisterijen. Amsterdam: Zelfzorg, 2010. 